\title{
DEGRADACIÓN DE DUNAS LITORALES DE CHILE CENTRAL: UNA VISIÓN BIOGEOMORFOLÓGICA
}

\section{Degradação de dunas costeiras no Chile Central: uma visão biogeomorfológica}

\author{
Hermann Manríquez-Tirado ${ }^{1}$ \\ ${ }^{1}$ Instituto de Geografía, Pontificia Universidad Católica de Valparaíso, Chile. \\ E-mail: hermann.manriquez@pucv.cl. \\ Proyecto Fondecyt Iniciación $\mathrm{n}^{\circ} 11181093$
}

\section{RESUMEN}

Los campos de dunas costeras de Chile central son resultado de las interacciones entre las variaciones glacioeustáticas del nivel del mar, cambios climáticos y el solevantamiento tectónico de la costa ocurridos durante el Cuaternario. La evolución actual es debida a morfodinámicas naturales ligadas al viento, la vegetación y a la ocupación e instalación de actividades e infraestructuras humanas. Se evidencia la degradación de dos campos de dunas en Chile central debido a la extensión de especies vegetales invasivas y la instalación de especies arbóreas productivas. Se aprecian alteraciones de las dinámicas eólicas y con ello se espera la modificación de las morfologías existentes.

Palabras clave: dunas litorales, biogeomorfología, Chile central, especies invasivas.

\section{RESUMO}

Os campos de dunas costeiras do centro do Chile são o resultado das interações entre as variações glacioeustáticas do nível do mar, as mudanças climáticas e o esgoto tectônico da costa durante o Quaternário. A evolução atual se deve à morfodinâmica natural ligada ao vento, à vegetação e à ocupação e instalação de atividades e infraestrutura humanas. A degradação de dois campos de dunas no centro do Chile é evidente devido à extensão de espécies invasoras de 
plantas e à instalação de espécies produtivas de árvores. Alterações na dinâmica do vento são apreciadas e com isso a modificação das morfologias existentes é esperada.

Palavras-chave: dunas costeiras, biogeomorfologia, centro do Chile, espécies invasoras.

\section{INTRODUCCIÓN}

Chile central concentra alrededor de dos tercios de la población del país. Excluyendo a la ciudad de Santiago como capital, los habitantes se localizan mayormente en ciudades litorales. Las costas de esta parte de Chile son el resultado de complejas interacciones que han ocurrido desde el Cuaternario, en las que han participado las variaciones glacioeustáticas del nivel del mar, el solevantamiento tectónico de la costa y los cambios climáticos. Por ello se encuentran cuatro unidades geomorfológicas principales: planicies litorales, acantilados, playas y dunas. Estas últimas son las que se encuentran mayormente afectadas por las actividades humanas, pues no tienen normativas legales que las protejan desde el punto de vista ambiental. Las dunas en Chile pueden ser consideradas como espacios de libertad, en el sentido de que ellas rompen la continuidad morfológica de la zona costera y han sido un obstáculo para el desarrollo urbano e industrial, que en esta parte del país adopta una configuración paralela a la línea de costa. Por otra parte, los campos de dunas son espacios altamente naturalizados permitiendo el desarrollo de numerosas especies vegetales y animales.

Las dunas litorales en Chile han sido estudiadas por diferentes autores bajo distintas ópticas de análisis: procesos erosivos, elementos de ordenamiento territorial, hábitat, control y estabilización, geomorfología y sedimentología (Vita \& Cogollor, 1979; Ramírez et al., 1985; Araya-Vergara, 1989; Castro, 1984-85; Ramírez, 1992; Andrade \& Hidalgo, 1997; Paskoff et al., 2002; Paskoff y Manríquez, 2004). La extensión del fenómeno dunario litoral en Chile no es del todo conocido con precisión, en 1966 una publicación oficial inventarió 131.000 ha de dunas (activas y estabilizadas) entre los $29^{\circ} \mathrm{S}$ y $42^{\circ} \mathrm{S}$ (Iren, 1966); más recientemente se contabilizó una superficie de 7.465 ha en 13 campos dunarios localizados entre los $29^{\circ} \mathrm{S}$ y $33^{\circ} \mathrm{S}$ (Castro, 2015).

La evolución actual de las dunas litorales de Chile central está asociada a su comportamiento morfodinámico debido a procesos naturales y a los procesos antrópicos que ocurren sobre ellas. Ambos fenómenos se observan en la costa de Chile central y que han provocado incluso la desaparición completa de alguna de estas unidades, es por ello que una amenaza permanente sobre las dunas son las crecientes necesidades de espacio para la instalación y desarrollo de múltiples usos del suelo que compiten es este espacio restringido desde el punto de vista espacial.

Una parte importante de las investigaciones publicadas en revistas especializadas centra el interés en las dinámicas de antedunas y playas y en las relaciones con la vegetación bajo el concepto de la biogeomorfología (Tobias, 2015; Keisers et al., 2016). En este sentido, las dunas también se encuentran amenazadas por la rápida expansión de especies vegetales invasivas que provocan perturbaciones en las dinámicas eólicas y la alteración y reemplazo de ecosistemas. En este sentido, se plantea como interesante conocer las características de la morfodinámica dunaria y las singularidades de las amenazas existentes. 


\section{MATERIALES Y MÉTODOS}

De los varios campos de dunas existentes en Chile central se han seleccionado los de Longotoma ( $32^{\circ} 23^{\prime} \mathrm{S}$ ) y de Ritoque (32 $\left.49^{\prime} \mathrm{S}\right)$, que cuentan con cartografía y aerofotografías para diferentes años (Figura 1).

Figura 1 - Localización de los campos de dunas de Longotoma y Ritoque en la costa de Chile central

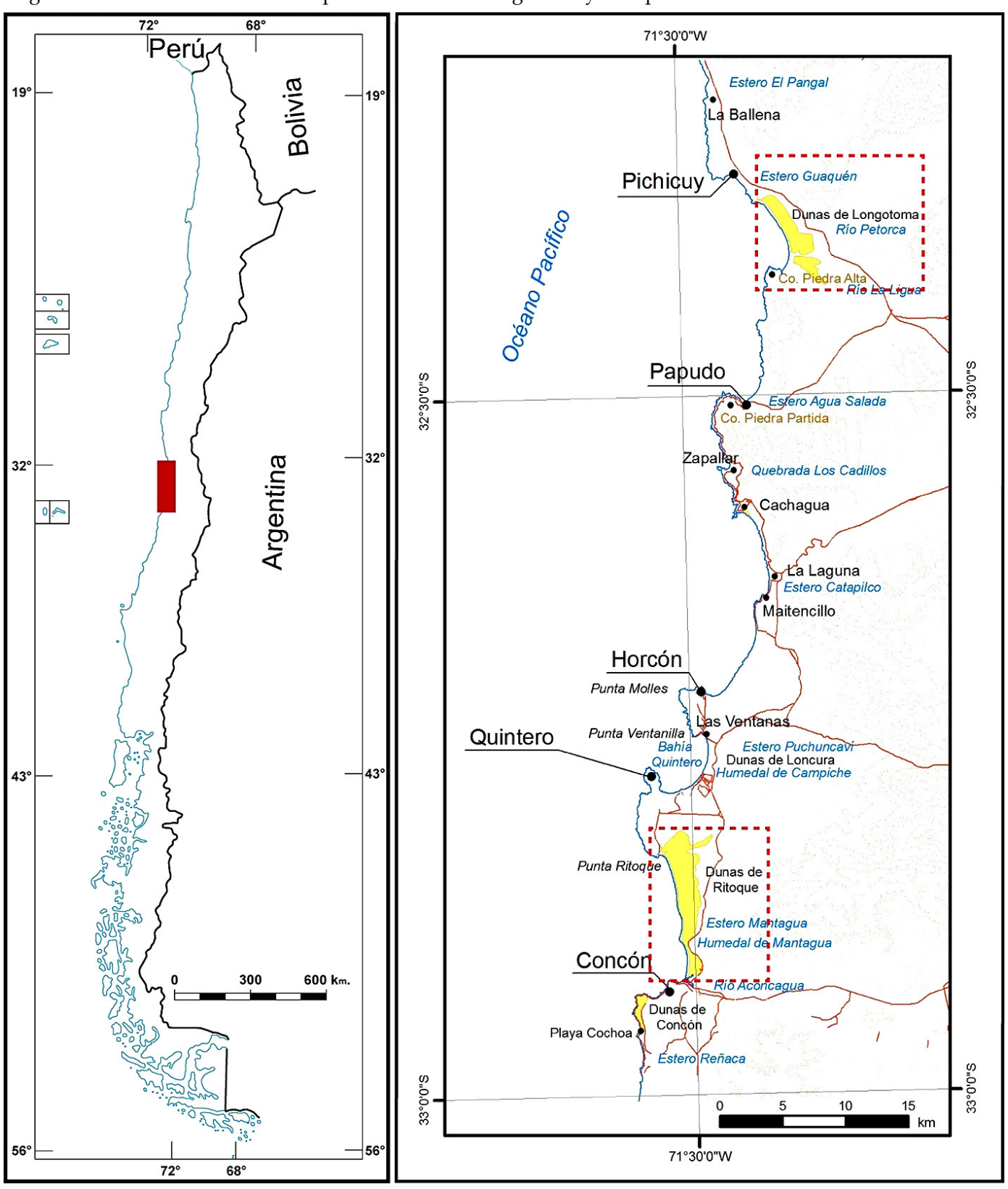

Los documentos cartográficos más antiguos corresponden a los de la década de 1920 publicados por el Instituto Geográfico Militar de Chile (IGM) a la escala de 1:25.000. Las fotografías aéreas verticales disponibles corresponden a las misiones aéreas que logran cubrir estos mismos campos de dunas: Hycon (1955) y Geotec (1996) (pertenecientes al IGM); y las imágenes satelitales de Google Earth para los años 2003, 2010 y 2018. 
Las observaciones de terreno se realizaron preliminarmente a través de recorridos pedestres con el objeto de reconocer las especies vegetales principales identificándolas como nativas o foráneas. Se realizaron además vuelos con dron (UAV) permitiendo reconocimientos rápidos de aquellas áreas de mayor dificultad de acceso.

Para conocer los cambios de extensión superficial se escanearon los documentos cartográficos y fotográficos a una resolución de 1200 dpi y se utilizó el sistema de información geográfico ArcGis para la georreferenciación de todas las imágenes recopiladas al datum WGS84. Posteriormente se realizó la digitalización de las áreas de duna expuesta y cubierta con vegetación, permitiendo el cálculo de superficie para cada una de ellas, obteniéndose valores en hectáreas.

\section{RESULTADOS}

Los campos de dunas estudiados muestran reducciones de superficie libre de vegetación de diferente consideración (Tabla I), el cálculo fue obtenido a partir de mediciones realizadas con un SIG, sobre documentos cartográficos, fotografías aéreas e imágenes satelitales. Las razones de esta disminución son evaluadas preliminarmente a partir del estudio de los mismos documentos utilizados como fuente de información además de constataciones de terreno. El detalle específico se analiza en cada caso.

Tabla I - Superficie de campos de dunas libre de vegetación (ha)

\begin{tabular}{|l|c|c|c|c|c|c|}
\cline { 2 - 7 } \multicolumn{1}{c|}{} & \multicolumn{7}{c|}{ Años } \\
\hline Campo de dunas & 1920 & 1955 & 1996 & 2003 & 2010 & 2018 \\
\hline Longotoma & 633 & 633 & 584 & 543 & 513 & 430 \\
\hline Ritoque & 2.005 & 2.005 & 1.775 & 1.767 & 1.619 & 1.478 \\
\hline
\end{tabular}

\section{Campo de dunas de Longotoma}

Se localiza frente a la bahía La Ligua. El gran campo de dunas está dividido en dos unidades, separadas por el río Petorca, cuya cuenca tiene una superficie de $1.988 \mathrm{~km}^{2}$. La unidad sur, de menor extensión, está constituida por dos tipos de formas: dunas longitudinales holocénicas estabilizadas con vegetación arbustiva y arbórea y dunas vivas transversales desprovistas de plantas (Paskoff \& Manriquez, 2004), que poseen un estrecho frente transgresivo, limitado por el río La Ligua cuya cuenca tiene una superficie de 1.980 $\mathrm{km}^{2}$, y que constituye el límite sur de esta unidad (Figura 2).

La unidad norte se encuentra bordeada al oeste por un acantilado muerto que es el límite una terraza marina. Se consideró como "unidad dunaria original", a la ocupada por la anteduna y las dunas transversales de dirección NO-SE. La carta topográfica de 1923 y la fotografía aérea de 1955, no muestran gran diferencia en cuanto a la superficie dunaria, que contabilizan un total de 633 hectáreas para esta unidad. Entre los años 1955 y 2018 la superficie libre se redujo en 203 hectáreas, por lo que en la actualidad el campo de dunas representa el 67,9\% de la unidad original (Figura 3). 
Figura 2 - Frente transgresivo de la unidad sur del campo de dunas de Longotoma. Se observa a las dunas transversales avanzando sobre el río Ligua. A la derecha se encuentran las dunas longitudinales holocénicas estabilizadas (Fotografía dron)

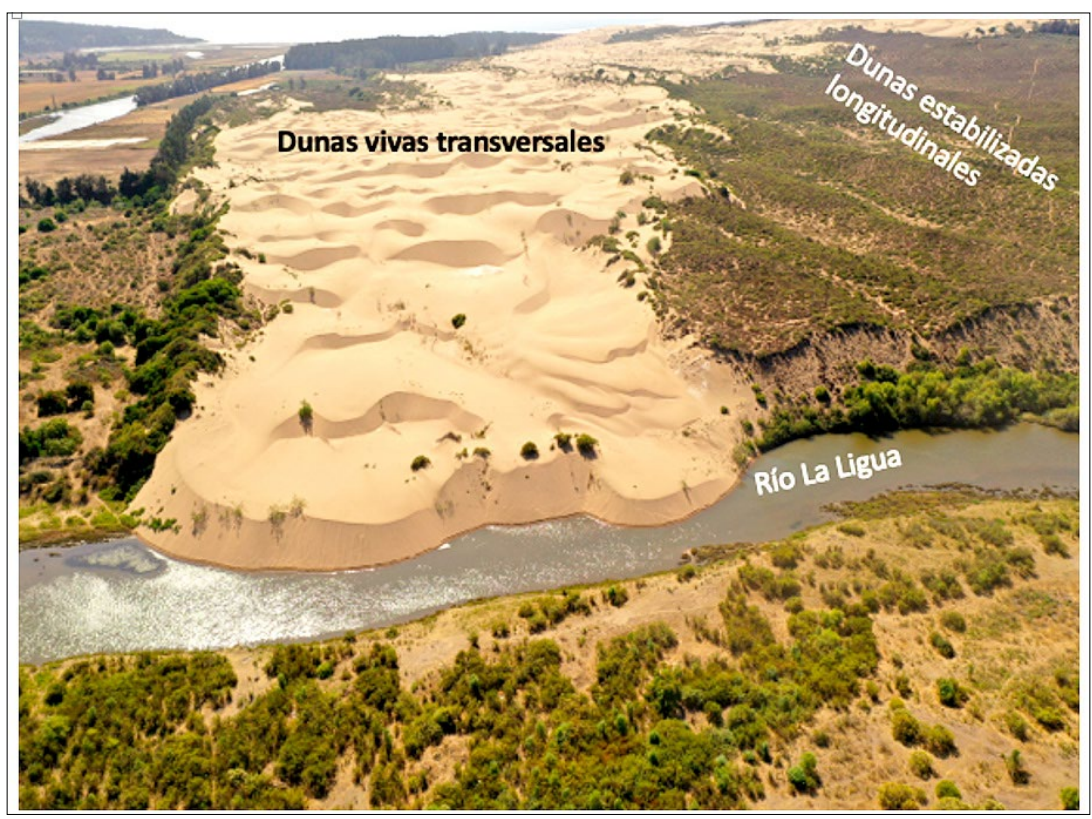

Figura 3 - Campo de dunas de Longotoma (subunidad norte) se aprecia que las dunas transversales, totalmente activas en 1955, se encuentran totalmente vegetalizadas hacia el año 2018. La imagen de la izquierda corresponde a una cartografía del año 1923

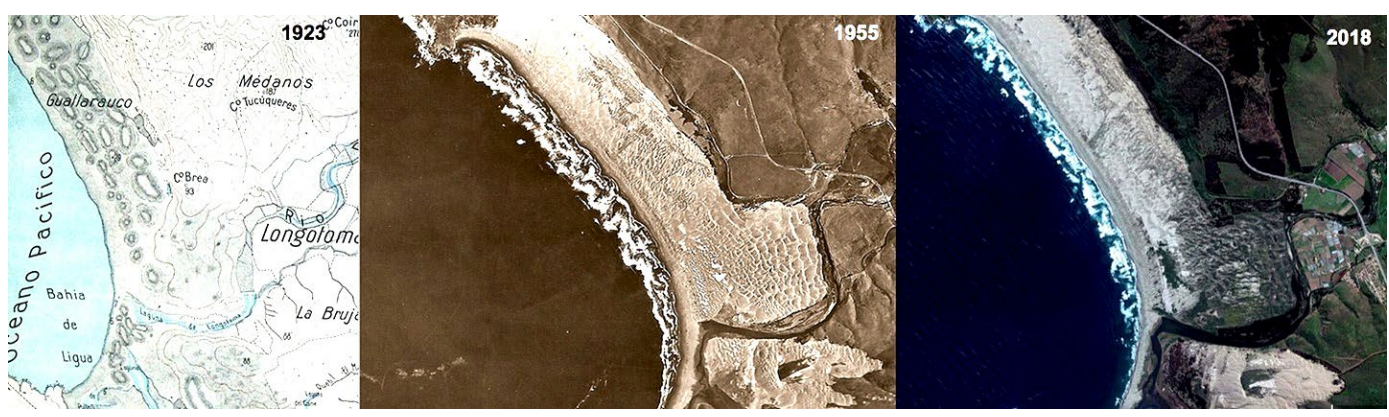

\section{Campo de dunas de Ritoque}

De mayor extensión que el campo de dunas de Longotoma, se encuentra ubicado inmediatamente al norte del río Aconcagua, cuya cuenca, que se extiende hasta la cordillera de los Andes, alcanza una superficie de 7.334 km², en razón de su tamaño esta cuenca es la explica el gran aporte sedimentario que alimenta este campo de dunas. Fue estudiado por Castro (1984, 1985), quien reconoció el desarrollo de varios tipos de dunas en un perfil transversal: anteduna, depresión interdunaria, dunas transversales, dunas longitudinales holocénicas y dunas antiguas pleistocénicas. Este campo dunario tuvo una superficie de 2.005 hectáreas libres de vegetación durante las primeras décadas del siglo XX. La reducción de superficie, entre el año 1955 y 2018, equivalente a 527 hectáreas, se debe a la instalación de plantaciones arbóreas como Pinus radiata D. Don y Eucalyptus globulus y Cupressus macrocarpa ubicadas principalmente en el sector norte, en la depresión interdunaria y sobre las dunas transversales cercanas y el avance de especies arbustivas foráneas. Actualmente se conserva el 73,7\% del campo de dunas original (Figura 4). 


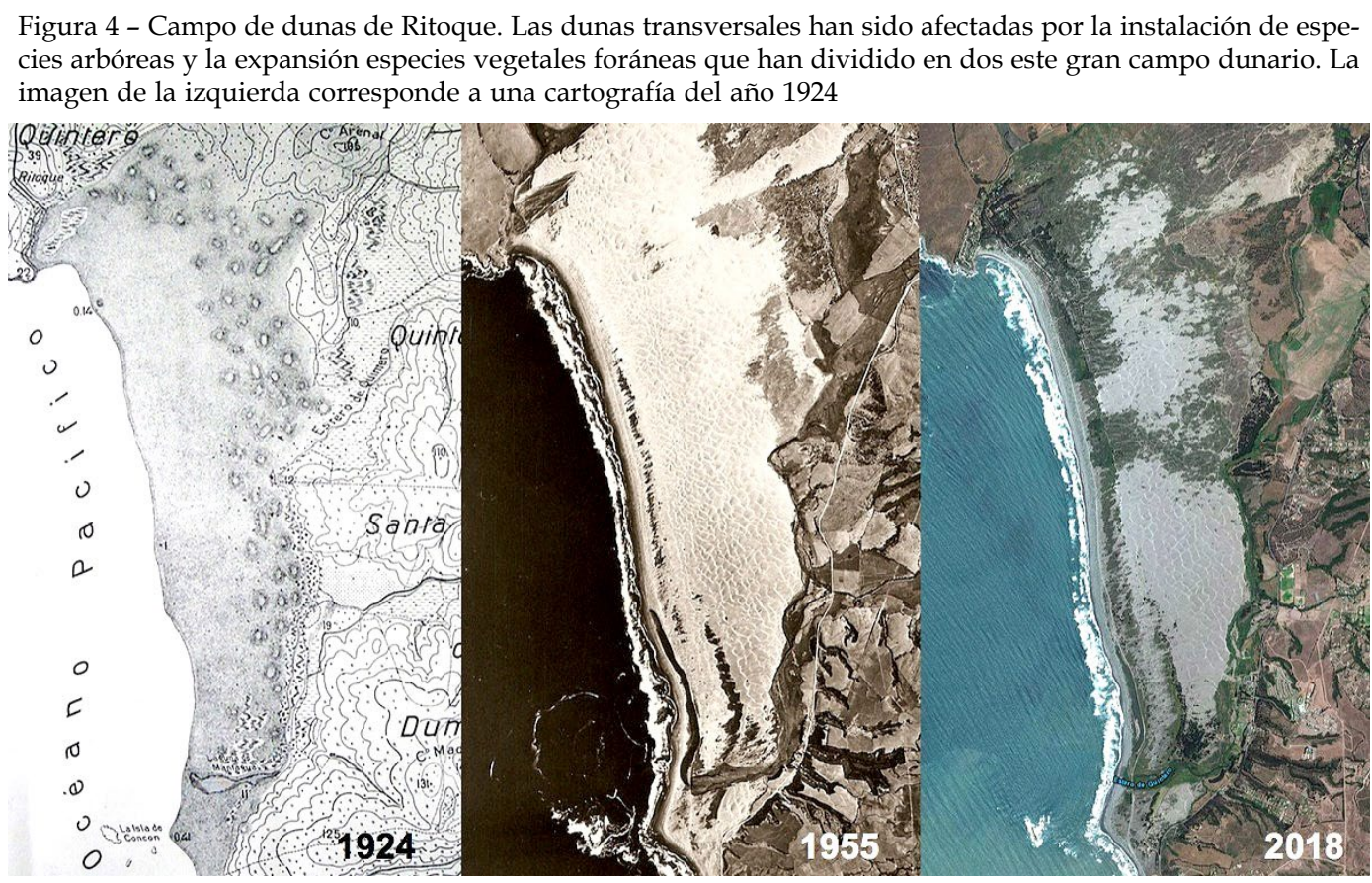

\section{La vegetación y las dunas}

Las especies vegetales que se encuentran en estos campos dunarios tienen la habilidad de retener muy bien las arenas, iniciando la construcción de las formas a través de sistema radiculares densos que las hacen crecer en altura desde configuraciones embrionarias y aisladas, hasta formas complejas que adoptan alineamientos en función de los vientos predominantes. Plantas típicas de las antedunas en Ritoque y Longotoma son Ammophila arenaria y Ambrosia chamissonis (introducidas) y Carpobrotus aequilaterus (nativa), colonizan principalmente las crestas y laderas de barlovento, quedando la cara de sotavento como una superficie de deslizamiento de arena, en la que se encuentran estas mismas plantas, pero con diferentes niveles de cobertura; en los corredores de deflación, sin vegetación, se produce la movilización más activa de las arenas, que se extienden bajo la forma de lenguas arenosas hacia una depresión húmeda angosta, colonizada por especies nativas como Scirpus nodosus, Carpobrotus aequilaterus y Baccharis cóncava e introducidas como Lupinus arboreus. Las dunas longitudinales, más antiguas, son vegetalizadas con especies arbustivas y subarbustivas (como el Baccharis concava) que contribuyen a su fijación, sobre una superficie que ha permitido el desarrollo de suelos delgados. Las dunas transversales, son las más activas ya que presentan gran actividad morfodinámica y escasa vegetación en superficie, sin embargo en las partas bajas entre los alineamientos de dunas al abrigo de los vientos y más cerca humedad subsuperficial, han comenzado a ser colonizadas por Lupinus arboreus (Figura 5) en asociación con otras arbustivas y que desde estos lugares sube por las dunas y se extiende rápidamente provocando la alteración de las dinámicas eólicas sobre ellas.

A partir de la década de 1960 la Corporación Nacional Forestal (Conaf) desarrolló diversos programas que tuvieron como fin el control de dunas en Ritoque a través de la instalación de plantas que permitieran la retención de arena. Fueron introducidas especies vegetales (Ammophila arenaria, Carpobrotus aequilaterus) que permitieron la formación de 
una anteduna, detrás de la cual fueron plantadas especies arbóreas (Cupressus macrocarpa, Pinus radiata) que se beneficiaron de la humedad de la depresión existente.

Figura 5 - Lupinus arboreus instalado en las dunas vivas transversales de Ritoque

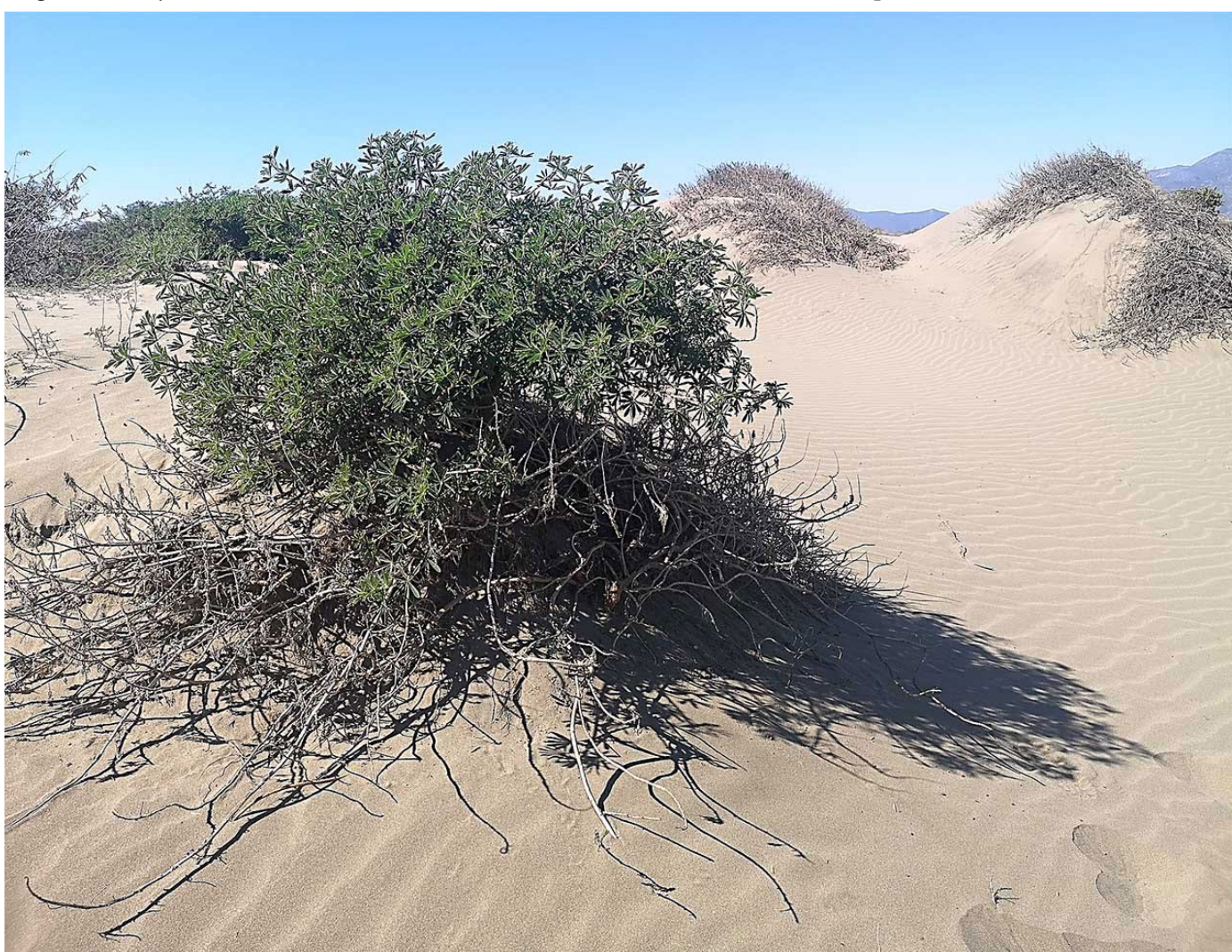

\section{CONCLUSIONES Y CONSIDERACIONES FINALES}

Las transformaciones que provocan la vegetación son especialmente observables en la anteduna, aquí las especies introducidas han logrado elaborar una unidad longitudinal paralela a la línea de costa de ancho variable, pero que se transforma en una unidad límite entre la playa y la depresión interdunaria. Las arenas que logran escapar desde la anteduna hacia el interior lo hacen a través de los corredores de deflación desprovistos de vegetación. En esta depresión la napa subterránea tiene un comportamiento estacional de su profundidad, la humedad permite que se desarrollen bastante bien especies vegetales higrófitas y en donde también alcanza coberturas importantes el Lupinus arboreus, atrapando la arena e imposibilitando su paso hacia el área de dunas vivas transversales que evolucionan de acuerdo a la importancia del viento, pero al parecer con aportes diferenciados de arena de acuerdo al sector considerado (Figura 6). Una investigación de mayor detalle posibilitará conocer la magnitud de las interacciones de los flujos de arena y la vegetación que construye dunas, bajo la óptica de la biogeomorfología y sus funciones de bioconstrucción y bioprotección. 
Figura 6 - Unidades morfológicas en el campo de dunas de Ritoque. La Depresión interdunaria tiene una mayor variedad de especies vegetales y alcanza altos porcentajes de cobertura

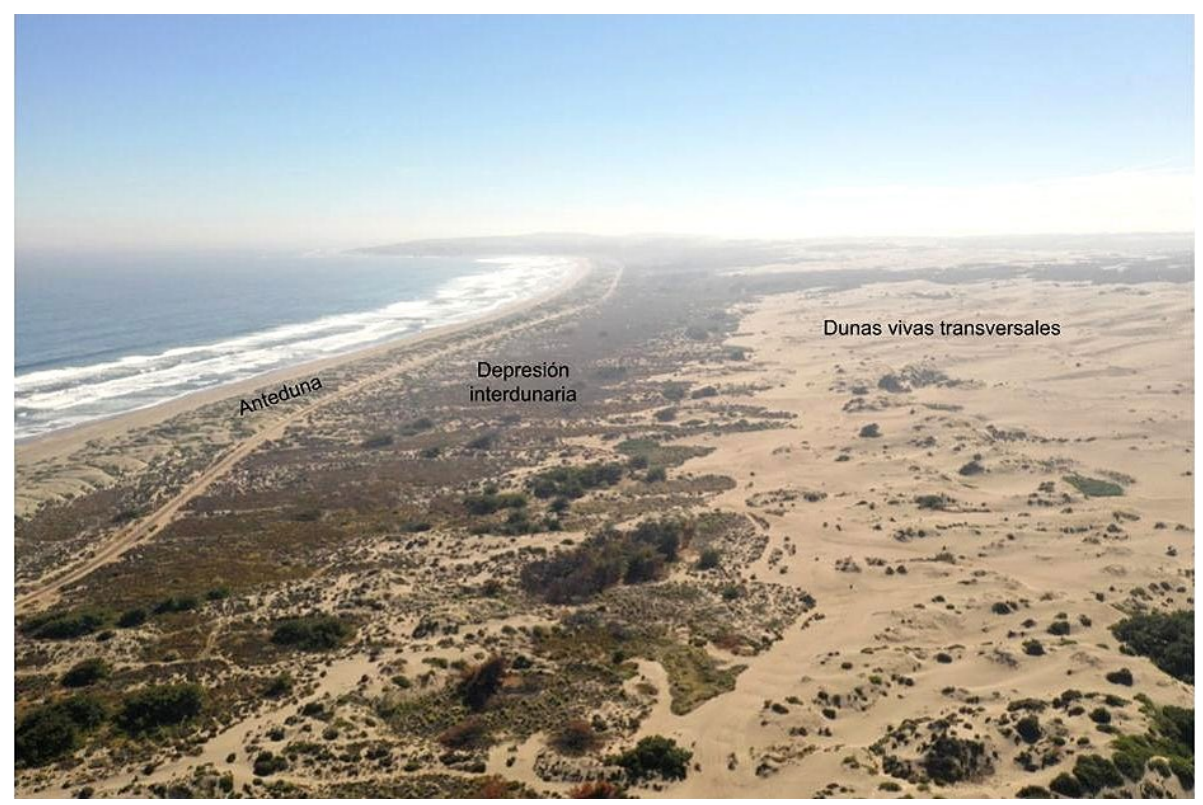

(Fotografía dron).

Agradecimientos - El autor agradece el financiamiento del Proyecto Fondecyt de Iniciación n $n^{0} 11181093$, con el cual se desarrolla la investigación que da cuenta este artículo.

\section{REFERENCIAS BIBLIOGRÁFICAS}

Araya-Vergara, J. Remnant coastal dunes and their significance in chilean ergs, in Second International Conference on Geomorphology Geoöko-Plus 1, Darmstadt: 15, 1989.

Andrade, B. \& Hidalgo, R. Desarrollo urbano en el litoral de la provincia de Petorca: una aproximación desde los instrumentos de planificación territorial y fragilidad del medio físico. Revista de Geografía Norte Grande, v. 24, p. 157-164, 1997.

Castro, C. Geografía de las dunas costeras de Chile. Instrumentos y pautas para su manejo integrado. Textos Universitarios, PUC, 275 p., Santiago, 2015.

Castro, C. Reseña del estado actual de conocimiento de las dunas litorales en Chile. Terra Australis 28, p. 13-32, 1984-85.

Instituto de Recursos Naturales (IREN). Inventario de dunas en Chile, publicación $\mathrm{n}^{\mathrm{o}} 4$, Santiago, 1966.

Keijsers, J.G.S.; De Groot, A.V. \& Riksen, M.J.P.M. Modeling the biogeomorphic evolution of coastal dunes in response to climate change, J. Geophys. Res. Earth Surf., v. 121, p. 11611181, 2016.

Paskoff, R. \& Manriquez, H. Las dunas de las costas de Chile. Santiago: Instituto Geográfico Militar, 113 p., 2004.

Paskoff, R.; Manríquez, H.; Cuitiño, L. \& Petiot, R. Nuevos antecedentes acerca de la geomorfología de la duna colgada de Concón. Terra Australis, v. 47, p. 43-50, 2002. 
Ramírez, C. Las dunas chilenas como hábitat humano, florístico y faunístico. Bosque, v. 13, n. 1, p. 3-17, 1992.

Ramírez, C.; Durán, A.; Figueroa, H. \& Contreras, D. Estudio de la vegetación de dunas con técnicas estadísticas multivariadas. Revista Geográfica de Valparaíso, v. 16, p. 47-66, 1985.

Tobias, M. California foredune plant biogeomorphology. Physical Geography, v. 36, n. 1, p. 19-33, 2015.

Vita, A. \& Cogollor, G. Estudio del control de las dunas de Ritoque. Universidad de Chile. Facultad de Ciencias Forestales. Departamento de Silvicultura. Santiago, 1979. 